ARTICLE

\title{
A biosynthetic model of cytochrome $c$ oxidase as an electrocatalyst for oxygen reduction
}

Sohini Mukherjee, Arnab Mukherjee ${ }^{2}$, Ambika Bhagi-Damodaran², Manjistha Mukherjee ${ }^{1}$, Yi Lü \& Abhishek Dey ${ }^{1}$

Creating an artificial functional mimic of the mitochondrial enzyme cytochrome $c$ oxidase $(\mathrm{C} \mathrm{CO})$ has been a long-term goal of the scientific community as such a mimic will not only add to our fundamental understanding of how $\mathrm{CcO}$ works but may also pave the way for efficient electrocatalysts for oxygen reduction in hydrogen/oxygen fuel cells. Here we develop an electrocatalyst for reducing oxygen to water under ambient conditions. We use site-directed mutants of myoglobin, where both the distal $\mathrm{Cu}$ and the redox-active tyrosine residue present in $\mathrm{CcO}$ are modelled. In situ Raman spectroscopy shows that this catalyst features very fast electron transfer rates, facile oxygen binding and $\mathrm{O}-\mathrm{O}$ bond lysis. An electron transfer shunt from the electrode circumvents the slow dissociation of a ferric hydroxide species, which slows down native $\mathrm{CcO}$ (bovine $500 \mathrm{~s}^{-1}$ ), allowing electrocatalytic oxygen reduction rates of $5,000 \mathrm{~s}^{-1}$ for these biosynthetic models.

\footnotetext{
${ }^{1}$ Department of Inorganic Chemistry, Indian Association for the Cultivation of Science, 2A\&2B Raja SC Mullick Road, Jadavpur Kolkata 700032, India. ${ }^{2}$ Department of Chemistry, University of Illinois at Urbana-Champaign, Champaign, Illinois 61801, USA. Correspondence and requests for materials should be addressed to A.D. (email: icad@iacs.res.in).
} 
M imicking the sophistication of naturally occurring enzymes has been a long-term goal of the scientific community. An artificial analogue that can perform equally well as its natural predecessor will not only provide deeper understanding of the native enzymes, but also enable the development of efficient artificial catalysts. For several decades now chemists have embarked on this daunting pursuit of emulating the efficiency and selectivity of naturally occurring enzymes and several important milestones have been achieved. Efforts from synthetic inorganic chemists have resulted in synthetic models of myoglobin $(\mathrm{Mb})$, galactose oxidase, tyrosinase, cytochrome $\mathrm{P} 450$ and cytochrome $c$ oxidase $(\mathrm{CcO})^{1-5}$. Alternatively, there has been fervent pursuit of biochemical constructs inspired by natural metalloenzymes. A series of binuclear non-haem iron, cytochrome $c$, haem oxidases and iron-sulfur enzyme models have resulted from such efforts ${ }^{4,6-12}$. While none of the synthetic or biochemical models reported so far could match the reactivity exhibited by their natural counterparts, fundamental insights regarding the structurefunction correlations of several metalloenzymes have been gained in the process ${ }^{7,13-15}$. In addition, key information about the secondary coordination sphere interactions present in the protein-active site, which play a dominating role in determining the electronic structure and reactivity of these metalloenzymes, have been identified ${ }^{16,17}$.

In a biosynthetic approach, stable naturally occurring proteins have been used as scaffolds for creating mimics of several metalloenzymes, such as hydrogenases which are involved in the reversible generation of $\mathrm{H}_{2}$ from water, haem proteins participating in electron transfer and $\mathrm{O}_{2}$-binding, non-haem iron and copper enzymes active in small molecule activation, and even novel enzymes containing non-native cofactors $^{18-24}$. For example, using this approach, biosynthetic models that structurally and functionally mimic $\mathrm{C} c \mathrm{O}$ and nitric oxide reductase have been reported ${ }^{7,25}$. Despite decades of focused effort, however, biosynthetic models with catalytic efficiencies approaching those of the naturally occurring metalloenzymes have remained elusive ${ }^{26-28}$. In this report, we communicate a biosynthetic model of $\mathrm{C} C \mathrm{O}$ bearing the distal $\mathrm{Cu}_{\mathrm{B}}$ and a tyrosine residue that is kinetically more competent in reducing $\mathrm{O}_{2}$ electrochemically than any known synthetic analogue, as well as native $\mathrm{CcO}$ itself.

$\mathrm{X}$-ray crystallography of $\mathrm{Mb}$ and its mutant have revealed that its two propionate side chains project out of the protein surface into the solvent (Fig. 1) $)^{7}$. Taking advantage of this structural feature, we have previously developed an electrocatalytic $\mathrm{O}_{2}$ reduction system where the native haem cofactor in $\mathrm{Mb}$ is replaced by a modified hemin cofactor bearing an alkyne group (Hemin-yne, Fig. 2) so that electrons can be injected directly into the haem from a gold electrode to facilitate $\mathrm{O}_{2}$ reduction $^{29}$. This method resulted in a Mb-functionalized electrode bearing $2.15 \times 10^{-12} \mathrm{~mol}$ per $\mathrm{cm}^{2}$ of protein, which was characterized using several microscopic and spectroscopic techniques ${ }^{29}$. Over the last few years, a biosynthetic model of $\mathrm{CcO}$ has been reported in which two distal residues of Mb (L29 and F43) have been mutated to His, which along with the native His64, form a $\mathrm{Cu}$-binding site, mimicking the distal $\mathrm{Cu}_{\mathrm{B}}$-binding site present in $\mathrm{CcO}\left(\mathrm{Cu}_{\mathrm{B}} \mathrm{Mb}\right)^{30}$. Furthermore, in an attempt to mimic the conserved Tyr 244 residue in the $\mathrm{CcO}$-active site, a $\mathrm{G} 65 \mathrm{Y}$ mutant of $\mathrm{Cu}_{\mathrm{B}} \mathrm{Mb}\left(\mathrm{G} 65 \mathrm{YCu}_{\mathrm{B}} \mathrm{Mb}\right)$ containing redox-active tyrosine residue in the distal site and a variant where a tyrosine residue was crosslinked to the active site histidines were also created (Fig. 1) $)^{31}$.

Herein we report the electrocatalytic properties of the $\mathrm{G}_{6} \mathrm{YCu}_{\mathrm{B}} \mathrm{Mb}$ (higher synthetic yields than the tyrosine crosslinked variant) immobilized on an Au electrode using the method developed for $\mathrm{WT} \mathrm{Mb}^{29}$.

\section{Results}

Electrode characterization by SERRS. Surface-enhanced resonance Raman spectroscopy (SERRS) data (Fig. 3a) of the electrodes bearing the $\mathrm{G} 65 \mathrm{YCu}_{\mathrm{B}} \mathrm{Mb}$ protein with and without $\mathrm{Cu}_{\mathrm{B}}$ show the oxidation and spin state marker $v_{4}, v_{3}, v_{2}$ and $v_{10}$ bands at $1,375 \mathrm{~cm}^{-1}, 1,493 \mathrm{~cm}^{-1}, 1,585 \mathrm{~cm}^{-1}$ and $1,641 \mathrm{~cm}^{-1}$, respectively. The $v_{4}, v_{3}$ and $v_{2}$ values are consistent with the presence of a five-coordinated high spin haem in the active site on these electrodes bearing the biochemical constructs of $\mathrm{CcO}^{32}$. Also the bands at $1,504 \mathrm{~cm}^{-1}$ and $v_{4}$ at $1,641 \mathrm{~cm}^{-1}$ suggest the presence of a mixture of six-coordinate low spin species, which likely has $\mathrm{H}_{2} \mathrm{O}$ as the axial ligand. The positions of these bands in the $\mathrm{G}_{65} \mathrm{YCu}_{\mathrm{B}} \mathrm{Mb}$ and their relative intensities are different from Hemin-yne (Supplementary Fig. 1$)^{29}$.

Electrode characterization by $\mathrm{X}$-ray photoelectron spectroscopy. X-ray photoelectron spectroscopic (XPS) data of a $\mathrm{G}^{6} 5 \mathrm{YCu}_{\mathrm{B}} \mathrm{Mb}$ bound $\mathrm{Au}$ electrode clearly indicate the presence of $\mathrm{Fe}, \mathrm{Cu}, \mathrm{C}, \mathrm{N}$ and O elements (Supplementary Fig. 2, Supplementary Table 1). The $3 p_{3 / 2}, 2 p_{3 / 2}$ and $2 p_{1 / 2}$ binding energy peak for the Fe ${ }^{\mathrm{III}}$ of haem group appear at $56.5 \mathrm{eV}, 709.4 \mathrm{eV}$ and $722.4 \mathrm{eV}$, respectively ${ }^{33,34}$. The $2 p_{3 / 2}$ and $2 p_{1 / 2}$ binding energy peak for $\mathrm{Cu}^{\mathrm{II}}$ in the distal site appear at $931.7 \mathrm{eV}$ and $951.8 \mathrm{eV}$, respectively ${ }^{35}$. The $\mathrm{N}_{1 \mathrm{~s}}$
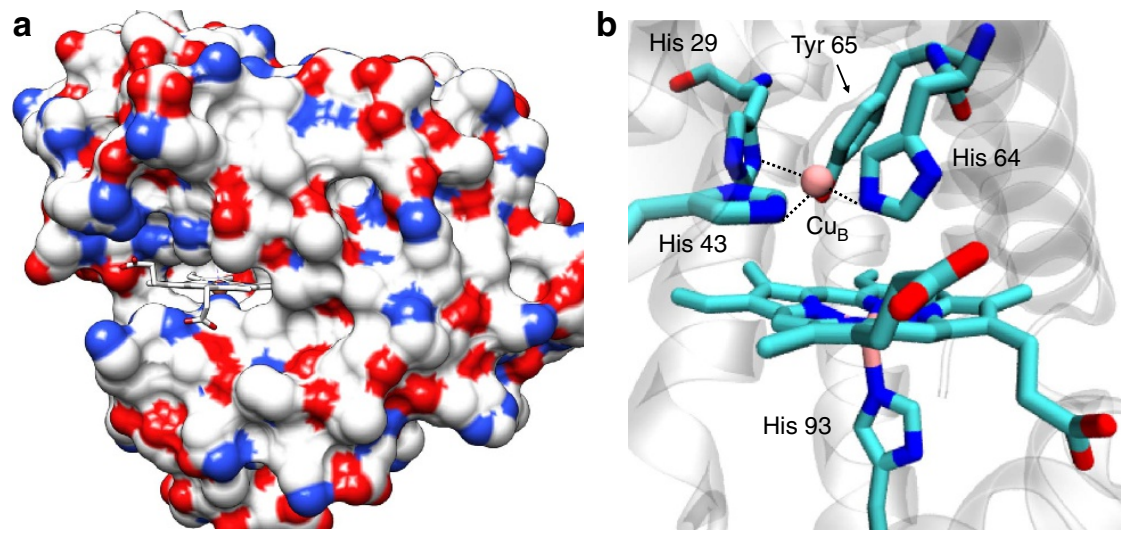

Figure 1 | Crystal structure. Crystal structure of a Mb-based biosynthetic model of CcO, F33Y-CuBMb; pdb id: 4FWY. (a) The haem cofactor is in a cleft on the molecule protein surface, (colour coded according to the charge of the residues), with the propionate groups exposed to the solvent. (b) The computer model of $\mathrm{G} 65 \mathrm{YC} \mathrm{U}_{\mathrm{B}} \mathrm{Mb}$ showing its catalytic centre containing the distal $\mathrm{Cu}_{\mathrm{B}}$ bound to histidines and a tyrosine 65 . 


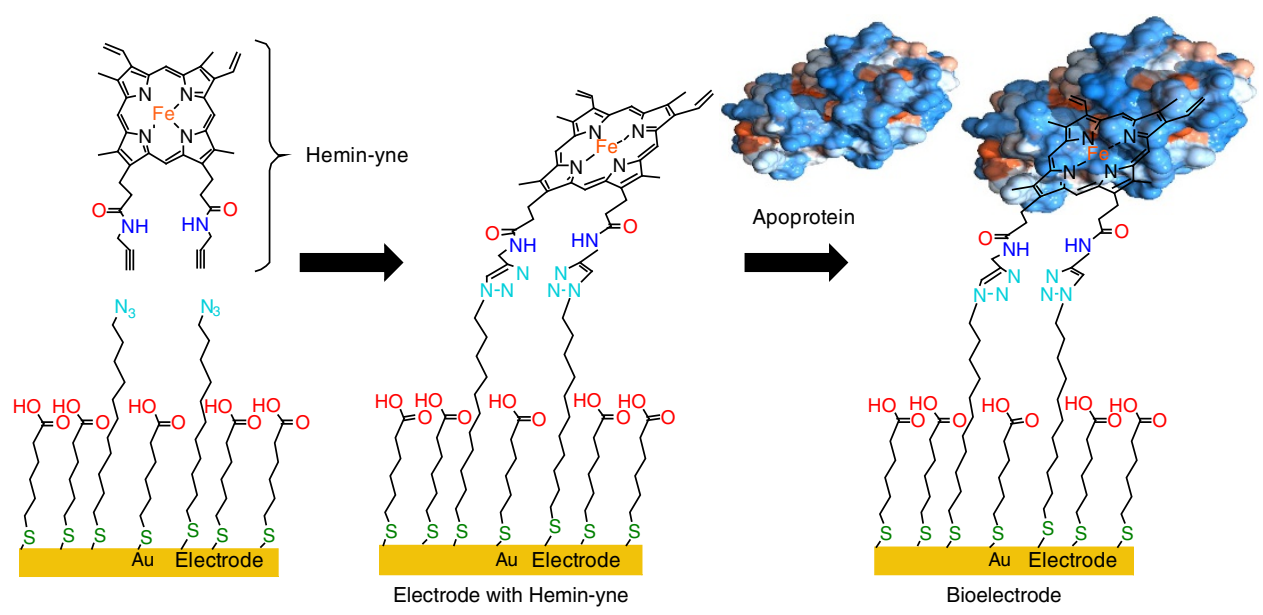

Figure 2 | Construction of the electrode bearing the biosynthetic model. Reconstitution of apoprotein in situ with Hemin-yne groups that are covalently attached to mixed self-assembled monolayers of thiols on an Au electrode. The modified hemin is indicated as Hemin-yne.

a

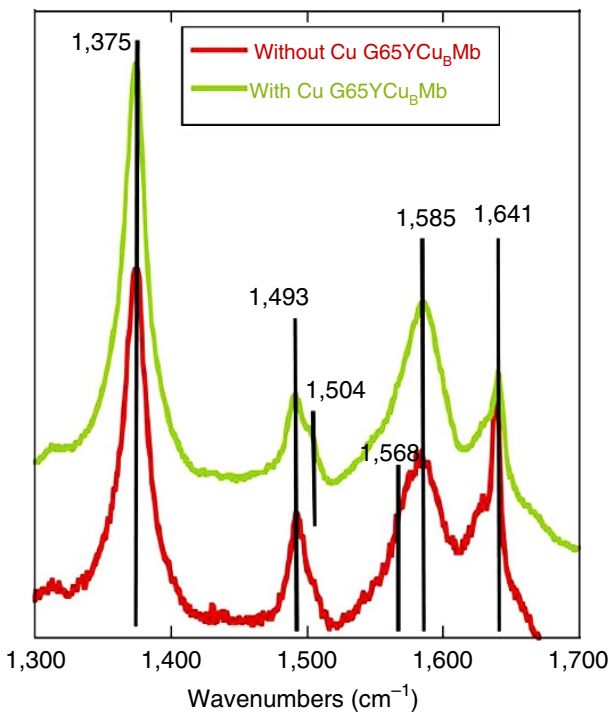

b



Figure 3 | SERRS and CV data for the electrode fabricated with G65YCu $\mathbf{C u}_{\mathbf{B}} \mathbf{M b}$ mutant. (a) SERRS spectra of $\mathrm{G} 65 \mathrm{YCu}_{\mathrm{B}} \mathrm{Mb}$ with (green) and without (red) the distal $\mathrm{Cu}^{2+}$ in air-saturated $100 \mathrm{mM}$ phosphate buffer $\left(\mathrm{pH}\right.$ 7) solution. (b) Anaerobic $\mathrm{CV}$ of $\mathrm{G} 65 \mathrm{YCu}_{\mathrm{B}} \mathrm{Mb}$ without $\mathrm{Cu}_{\mathrm{B}}$ (red) and after $\mathrm{Cu}_{\mathrm{B}}$ binding (green). $2 \mathrm{Vs}^{-1}$ scan rate, in degassed, $\mathrm{pH} \mathrm{7,100} \mathrm{mM}$ phosphate buffer using a Pt counter electrode. peak is broad (Supplementary Fig. 2), as it contains several components due to the presence of amide, haem pyrroles and the triazole groups (resulting from the covalent attachment of Heminyne) on the surface ${ }^{33}$. Similarly, the $C_{1 s}$ peak (Supplementary Fig. 2) contains contributions from different types of $\mathrm{C}$ atoms (aromatic, aliphatic, haem and so on) on these protein-modified surfaces $^{36}$.

Electrode characterization by $\mathrm{CV}$. Cyclic voltammetry $(\mathrm{CV})$ of $\mathrm{G} 65 \mathrm{YCu}_{\mathrm{B}} \mathrm{Mb}$ with and without the distal $\mathrm{Cu}_{\mathrm{B}}$ immobilized onto the electrodes in degassed buffer show the haem $\mathrm{Fe}^{3+/ 2+}$ midpoint reduction potential $\left(E^{1 / 2}\right)$ at $-97 \mathrm{mV}$ and $-57.5 \mathrm{mV}$, respectively (Fig. $3 \mathrm{~b}$ ). The peak separation between the cathodic and the anodic peak for both the cases is $\sim 70 \mathrm{mV}$ (ref. 37). Hemin-yne displays the $\mathrm{Fe}^{3+/ 2+}$ reduction potential at $-70.0 \mathrm{mV}$ in the absence of a protein and $-135.0 \mathrm{mV}$ when bound to wild-type apo $\mathrm{Mb}^{29}$. In the case of the $\mathrm{G} 65 \mathrm{YCu}_{\mathrm{B}} \mathrm{Mb}$ protein-bound electrodes, the $\mathrm{Cu}^{2+I+}$ process overlaps with the Hemin-yne $\mathrm{Fe}^{3+/ 2+}$ process, resulting in approximately twice the area under these $\mathrm{CV}$ peaks relative to the $\mathrm{G} 65 \mathrm{YCu}_{\mathrm{B}} \mathrm{Mb}$ bearing electrodes prior to $\mathrm{Cu}_{\mathrm{B}}$ loading. The integrated area under these $\mathrm{CV}$ features in the absence of $\mathrm{Cu}^{2+}$ indicates that there are $2.55 \pm 0.05 \times 10^{-12} \mathrm{~mol}$ of protein per $\mathrm{cm}^{2}$ of the surface. The ratios of the integrated area under the $\mathrm{CV}$ features of $\mathrm{G} 65 \mathrm{YCu}_{\mathrm{B}} \mathrm{Mb}$ functionalized before and after loading the $\mathrm{Cu}_{\mathrm{B}}$ is $\sim$ 1:2 (Table 1, fourth column) which is consistent with the expected 1:1 stoichiometry (that is, every $\mathrm{G} 65 \mathrm{YCu}_{\mathrm{B}} \mathrm{Mb}$ binds one Hemin-yne and one $\mathrm{Cu}^{2}+$ ion). Note that the $E^{1 / 2}$ values of the hemin and $\mathrm{Cu}_{\mathrm{B}}$ measured for these electrodes are slightly different from those estimated from potentiometric titration in solution $^{7,19}$. This is likely due to the interfacial microenvironment of the -COOH-terminated Self Assembled Monolayer (SAM) which is known to shift the apparent formal potentials of redoxactive species in its vicinity ${ }^{38}$. Thus the in situ reconstitution of the protein with Hemin-yne on the electrode is evident from the SERRS, XPS (Supplementary Fig. 2) and CV data (Supplementary Fig. 3, Supplementary Fig. 4). The presence of the $\mathrm{Cu}^{2+}$ at $\mathrm{Cu}_{\mathrm{B}}$ site on the electrode is indicated by XPS and CV data. Taken together, these data indicate the assembly of the $\mathrm{G} 65 \mathrm{YCu}_{\mathrm{B}} \mathrm{Mb}$, biosynthetic model of $\mathrm{CcO}$ covalently attached to the electrode via the linkage between the Hemin-yne and the azide terminated thiols created using click reaction (Fig. 2).

$\mathrm{O}_{2}$ reduction reactivity of the electrode. In linear sweep voltammetry experiments performed in aerated buffers, large 
electrocatalytic $\mathrm{O}_{2}$ reduction currents are observed by the $\mathrm{G} 65 \mathrm{YCu}_{\mathrm{B}} \mathrm{Mb}$ (with and without $\mathrm{Cu}^{2+}$ ) bearing bio-electrodes at $\mathrm{pH} 7$ at room temperature, as the applied potential is lowered below $+100 \mathrm{mV}$ versus NHE (Fig. 4a, Supplementary Fig. 5). Thus as the potential of the electrode is lowered such that the iron in these proteins is reduced to $\mathrm{Fe}^{\mathrm{II}}$, an electrocatalytic $\mathrm{O}_{2}$ reduction current is observed. It is important to note that the potential of $\mathrm{O}_{2}$ reduction reaction $(\mathrm{ORR})\left(E_{\mathrm{ORR}}\right)$ is $-263 \mathrm{mV}$, which is more negative than the $E^{1 / 2}(-97 \mathrm{mV})$, suggesting that the potential determining step of ORR is not the reduction of resting $\mathrm{Fe}^{\mathrm{III}}$ to $\mathrm{Fe}^{\mathrm{II}}$ but the reduction of a different species with $-166 \mathrm{mV}$ more negative potential (Fig. $4 \mathrm{a}$ inset). A more negative $E_{\mathrm{ORR}}$ relative to $E^{1 / 2}$ is mechanistically significant (vide infra).

In these active sites, $\mathrm{O}_{2}$ may be reduced by $4 \mathrm{e}^{-}$and $4 \mathrm{H}^{+}$to $\mathrm{H}_{2} \mathrm{O}$, or by fewer electrons to produce partially reduced oxygen species (PROS) like $\mathrm{O}_{2}^{-}$and $\mathrm{H}_{2} \mathrm{O}_{2}$. The extent of $4 \mathrm{e}^{-}$reduction and the second order rate constant $\left(k_{\mathrm{ORR}}\right)$ of the ORR can be determined using rotating disc electrochemistry (RDE) where the catalytic $\mathrm{O}_{2}$ reduction current increases with increasing rotation rates (Fig. 4a,b) following the Kouteky-Levich (K-L) equation (equation (1)) $)^{39}$.

$$
i_{\text {cat }}^{-1}=i_{\mathrm{K}}(E)^{-1}+i_{\mathrm{L}}^{-1}
$$

where, $i_{\mathrm{K}}(E)$ is the potential-dependent kinetic current and $i_{\mathrm{L}}$ is the Levich current. $i_{\mathrm{L}}$ is expressed as

$$
i_{\mathrm{L}}=0.62 n F A\left[\mathrm{O}_{2}\right]\left(D_{\mathrm{O} 2}\right)^{2 / 3} \omega^{1 / 2} v^{-1 / 6}
$$

where $n$ is the number of electrons transferred to the substrate, $A$ is the macroscopic area of the disc $\left(0.096 \mathrm{~cm}^{2}\right),\left[\mathrm{O}_{2}\right]$ is the concentration of $\mathrm{O}_{2}$ in an air-saturated buffer $(0.26 \mathrm{mM})$ at $25^{\circ} \mathrm{C}$,

\begin{tabular}{|c|c|c|c|}
\hline Protein & Metal-binding sites & $E^{1 / 2}(m V)$ & Integrated coverage $\left(\mathrm{mol} \mathrm{cm}^{-2}\right)$ \\
\hline Hemin-yne reconstituted myoglobin 29 & 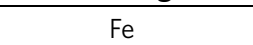 & $-135.0 \pm 5.0$ & $2.15 \pm 0.05 \times 10^{-12}$ \\
\hline Hemin-yne reconstituted $\mathrm{G} 65 \mathrm{YC} \mathrm{U}_{\mathrm{B}} \mathrm{Mb}$ & $\mathrm{Fe}$ & $-57.5 \pm 5.0$ & $2.55 \pm 0.05 \times 10^{-12}$ \\
\hline
\end{tabular}

Table 1 | $E^{1 / 2}$ and coverage.
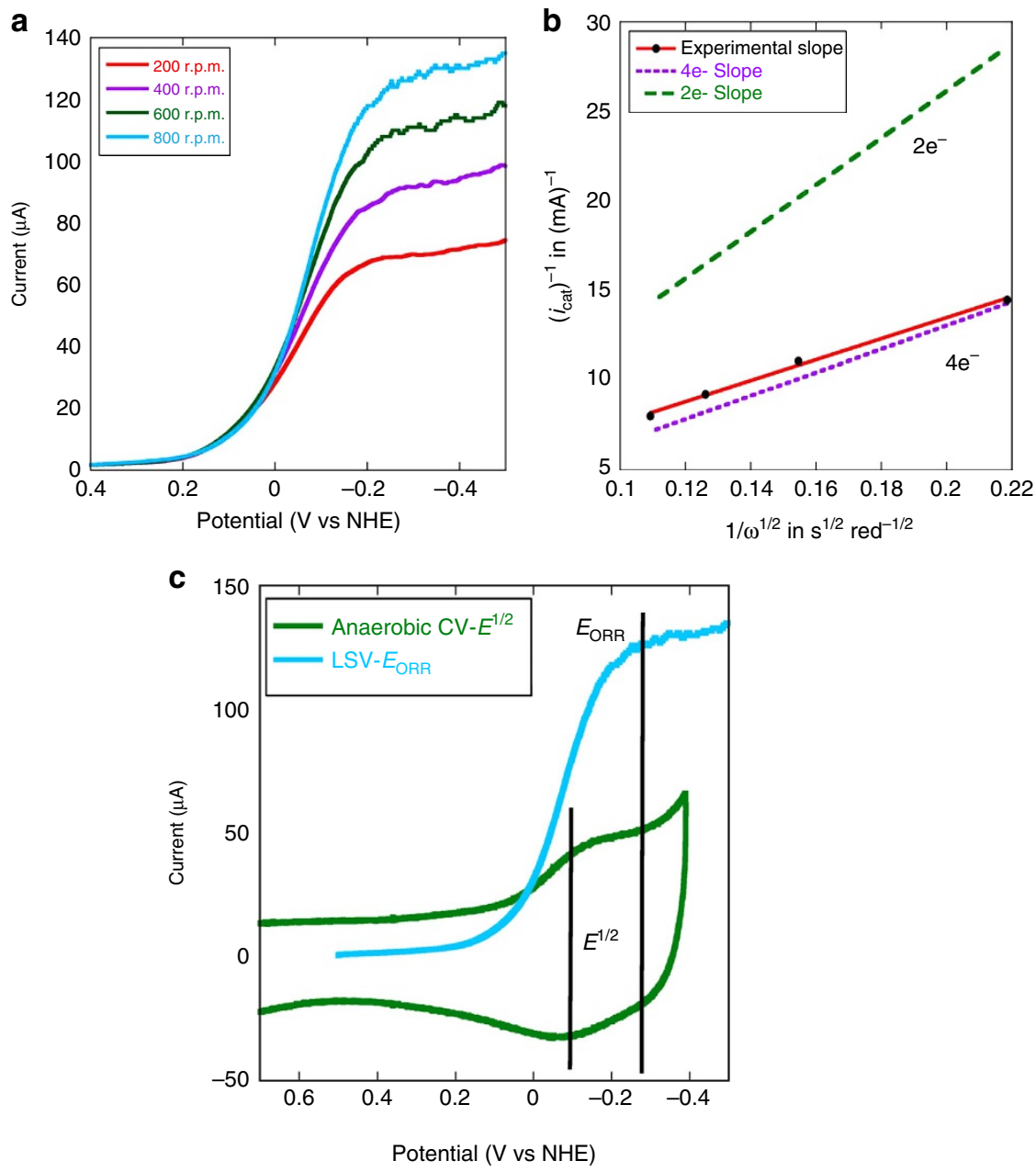

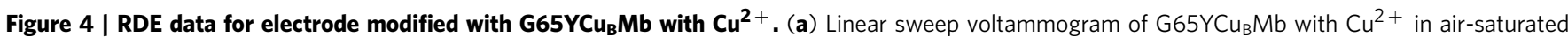
$\mathrm{pH} 7,100 \mathrm{mM}$ phosphate buffer solution at $100 \mathrm{mVs}^{-1}$ scan rate, potentials are scaled relative to NHE and a Pt counter electrode is used. Data are collected at different rotation speeds (200 r.p.m.-red, 400 r.p.m.-purple, 600 r.p.m.-green, 800 r.p.m.-blue). (b) Plot of $i_{\text {cat }}^{-1}$ for G65YCuB Mb-bearing bioelectrode at $-300 \mathrm{mV}$ potential and at multiple rotation rates, with the inverse square root of the angular rotation rate $\left(\omega^{-1 / 2}\right)(\mathbf{c})$ Difference between the potential for $\mathrm{O}_{2}$ reduction $\left(E_{\mathrm{ORR}}\right)$ and the midpoint reduction potential of $\mathrm{Fe}^{3+/ 2+}$ redox couple $\left(E^{1 / 2}\right)$. 
$D_{\mathrm{O} 2}$ is the diffusion coefficient of $\mathrm{O}_{2}\left(1.8 \times 10^{-5} \mathrm{~cm}^{2} \mathrm{~s}^{-1}\right)$ at $25^{\circ} \mathrm{C}, \omega$ is the angular velocity of the disc and $v$ is the kinematic viscosity of the solution $\left(0.009 \mathrm{~cm}^{2} \mathrm{~s}^{-1}\right)$ at $25^{\circ} \mathrm{C}$ (ref. 40 ).

Plot of $i_{\text {cat }}^{-1}$ at multiple rotation rates with the inverse square root of the angular rotation rate $\left(i_{\text {cat }}^{-1}\right)$ for $\mathrm{G} 65 \mathrm{YCu}_{\mathrm{B}} \mathrm{Mb}$ (with $\mathrm{Cu}^{2+}$ ) (Fig. $4 \mathrm{~b}$ ) is linear. The slope of $\mathrm{K}-\mathrm{L}$ plot is expressed as $1 /\left[n\left\{0.62 F A\left(D_{\mathrm{O} 2}\right)^{2 / 3} v^{-1 / 6}\right\}\right]$, which can be used to experimentally estimate the value of $n$ where $n$ is the number of electrons donated to the substrate, that is, $\mathrm{O}_{2}$. The slope obtained from the experimental data for $\mathrm{G} 65 \mathrm{YCu}_{\mathrm{B}} \mathrm{Mb}$ (Fig. 4b) is close to the theoretical slope (Fig. $4 \mathrm{~b}$, dotted purple line) expected for a $4 \mathrm{e}^{-}$process and very different from the slope for a $2 \mathrm{e}^{-}$ process (Fig. 4b, dotted green line). Thus the $\mathrm{G} 65 \mathrm{YCu}_{\mathrm{B}} \mathrm{Mb}$ bioelectrode predominantly catalyses a $4 \mathrm{e}^{-} / 4 \mathrm{H}^{+}$reduction of $\mathrm{O}_{2}$ to $\mathrm{H}_{2} \mathrm{O}$ at $\mathrm{pH} 7$.

The intercept of the $\mathrm{K}-\mathrm{L}$ plot is the inverse of the kinetic current $\left(i_{\mathrm{K}}(E)^{-1}\right)$, where $i_{\mathrm{K}}(E)$ is expressed as ${ }^{41}$

$$
i_{\mathrm{K}}(E)=k_{\mathrm{ORR}} n F A\left[\mathrm{O}_{2}\right] \Gamma_{\text {cat }}
$$

where, $n$ is the number of electrons, $A$ is the geometric surface area, $\left[\mathrm{O}_{2}\right]$ is the bulk concentration of $\mathrm{O}_{2}, \Gamma_{\text {cat }}$ is the surface coverage of the catalyst (obtained from the integration of the anaerobic $\mathrm{CV}$ data) and $k_{\mathrm{ORR}}$ is the second order rate constant for $\mathrm{O}_{2}$ reduction estimated at $-300 \mathrm{mV}$. At this potential, in an oxygenated buffer, the $\mathrm{G}_{6} \mathrm{YCu}_{\mathrm{B}} \mathrm{Mb}$ catalyst is involved in substrate diffusion-limited ORR. Using this equation (equation (3)) and the experimentally obtained $i_{\mathrm{K}}(E)$ at $-300 \mathrm{mV}$, the second order rate constant for $\mathrm{O}_{2}$ reduction G65 $\mathrm{YCu}_{\mathrm{B}} \mathrm{Mb}$ is evaluated to be $1.98 \times 10^{7} \mathrm{M}^{-1} \mathrm{~s}^{-1}$ (Table 2). The pseudo first order rate can be determined (Table 2) from the second order rate by taking into account the substrate, $\mathrm{O}_{2}$ concentration under these experimental conditions to be $0.26 \mathrm{mM}$ (Supplementary Fig. 6). The catalytic ORR rate by $\mathrm{G}_{65} \mathrm{YCu}_{\mathrm{B}} \mathrm{Mb}$ surpasses those reported for the best artificial synthetic analogues (Table 2).

The $\mathrm{G}_{65} \mathrm{YCu}_{\mathrm{B}} \mathrm{Mb}$ biosynthetic $\mathrm{Mb}$ scaffold-based bio-electrode for $\mathrm{O}_{2}$ reduction is remarkably stable. Monolayers bearing covalently attached $\mathrm{O}_{2}$-reducing electrocatalysts reported so far have never been stable enough to allow these dynamic electrochemical experiments to determine the kinetic parameters ( $k_{\mathrm{ORR}}$, number of electrons and so on). Enzymes like laccases, directly attached to chemically modified graphite electrodes, were found to be stable enough to be investigated with these hydrodynamic techniques ${ }^{27}$. The failure to perform these experiments has been attributed to degradation of the catalyst during RDE experiment, that is, very small turnover numbers presumably due to the production of PROS during ORR. Rotating ring disc electrochemistry (RRDE) shows formation of only $\sim 6 \%$ PROS by the G65YCu $\mathrm{Y}_{\mathrm{B}} \mathrm{Mb}$ (Supplementary Fig. 7) during ORR, indicating that it reduces $96 \%$ of $\mathrm{O}_{2}$ to $\mathrm{H}_{2} \mathrm{O}$ consistent with the RDE data. During the RDE experiments (Fig. 4a), the $\mathrm{G} 65 \mathrm{YCu}_{\mathrm{B}} \mathrm{Mb}$-functionalized electrodes bearing $10^{-12} \mathrm{~mol}$ of the catalyst reduced $1.8 \pm 0.3 \times 10^{-8} \mathrm{~mol}$ of $\mathrm{O}_{2}\left(7 \pm 1 \times 10^{-3} \mathrm{C}\right.$ total charge and $4 \mathrm{e}^{-}$per $\mathrm{O}_{2}$ molecule) yielding a turnover

\begin{tabular}{|c|c|c|c|}
\hline ORR catalysts & Metals & $k_{\text {ORR }}$ & $\begin{array}{l}\text { PROS } \\
(\%)\end{array}$ \\
\hline G65YCu $\mathrm{Mb}$ & $\begin{array}{c}\mathrm{Cu}_{\mathrm{B},} \\
\text { Haem }\end{array}$ & $\begin{array}{c}1.98 \times 10^{7} \mathrm{M}^{-1} \mathrm{~s}^{-1} \text { or } \\
5,148 \mathrm{~s}^{-1}\end{array}$ & $\sim 6 \pm 1$ \\
\hline $\begin{array}{l}\text { Synthetic } \\
\text { model } 60\end{array}$ & $\begin{array}{l}\mathrm{Cu}_{\mathrm{B}}, \\
\mathrm{Haem}\end{array}$ & 1. $2 \times 10^{5} \mathrm{M}^{-1} \mathrm{~s}^{-1}$ & $\sim 10 \pm 1$ \\
\hline
\end{tabular}

$\mathrm{ORR}, \mathrm{O}_{2}$ reduction reaction; $\mathrm{PROS}$, partially reduced oxygen species

$k_{\text {ORR }}$ determined at $-0.4 \mathrm{~V}$ versus NHE; PROS determined at $-0.12 \mathrm{~V}$ versus NHE in both cases. number of at least $10^{4}$. The role of PROS in degrading the catalyst is established by the fact that the electrolytic current (at $-0.3 \mathrm{~V}$ ) remains stable in the presence of $50 \mu \mathrm{M}$ catalase in solution (Supplementary Fig. 8).

\section{Discussion}

To understand the facile and selective $\mathrm{O}_{2}$ reduction catalysed by the $\mathrm{G} 65 \mathrm{YCu}_{\mathrm{B}} \mathrm{Mb}$ biochemical model, the recently developed SERRS-RDE technique is employed ${ }^{42}$. In this technique, the $r R$ spectra of the catalyst (that is, $\mathrm{G} 6 \mathrm{YCu}_{\mathrm{B}} \mathrm{Mb}$ ) bearing electrode is collected while the system is involved in steady state $\mathrm{O}_{2}$ reduction and the species accumulated in the steady state can be identified. For any species to accumulate in steady state, its rate of formation has to be greater than its rate of decay. Thus, while the species preceding the rate-determining step (rds) will accumulate at steady state, the accumulation of a species in steady state does not immediately imply its decay as the rds. In the absence of $\mathrm{O}_{2}$, a high spin ferrous species is formed, characterized by a $v_{4}$ and $v_{3}$ vibrations at $1,357 \mathrm{~cm}^{-1}$ and $1,473 \mathrm{~cm}^{-1}$ (Fig. 5a, cyan), respectively, when a cathodic potential of $-0.4 \mathrm{~V}$ is applied signifying reduction of the resting ferric state (Fig. 5a, red) to the active ferrous state at these potentials. However, when the same reducing potential is applied in an oxygenated buffer the SERRSRDE data (Supplementary Fig. 9) clearly show the presence of different species during electrocatalytic ORR, which leads to broadening of the $v_{4}, v_{3}$ and $v_{2}$ regions (Fig. $5 \mathrm{a}$, green) relative to the oxidized and reduced states (Fig. $5 \mathrm{a}$, red and cyan). In particular, the $v_{3}$ and $v_{2}$ vibrations discernibly shift to higher energies as indicated by clear increase in intensities at $1,508 \mathrm{~cm}^{-1}$ and $1,591 \mathrm{~cm}^{-1}$ (Fig. 4b), suggesting the accumulation of $\mathrm{Fe}^{\mathrm{IV}}=\mathrm{O}$ species during steady state $\mathrm{ORR}^{43}$. Signals from high spin ferrous, resting high spin ferric, low spin ferric and ferryl species with $v_{3}$ at $1,473 \mathrm{~cm}^{-1}$ (Fig. 5a, cyan; and Fig. 5b, brown), $1,493 \mathrm{~cm}^{-1}$ (Fig. 5a, red and Fig. 5b, dashed green), $1,504 \mathrm{~cm}^{-1}$ (Fig. 5a, cyan and Fig. 5b, cyan) and $1,508 \mathrm{~cm}^{-1}$ (Fig. 5a, green and Fig. 5b, green), respectively, could be convoluted by fitting the $v_{3}$ region of the spectrum. The lack of significant signal from the high spin ferrous species (weak $v_{3}$ at $1,473 \mathrm{~cm}^{-1}$ ) suggests that $\mathrm{O}_{2}$ binding to these species is facile in the steady state. These mutants use the basic design of $\mathrm{Mb}$ which has a very fast $\mathrm{O}_{2}$-binding rate $\left(10^{7} \mathrm{M}^{-1} \mathrm{~s}^{-1}\right)$ (refs 44,45). This rate is indeed $\sim 10$ times faster than $\mathrm{O}_{2}$ binding to the haem $\mathrm{a}_{3}$ site of $\mathrm{CcO}$ (ref. 46). Similarly, the very weak intensity of the high spin (HS) $\mathrm{Fe}^{\mathrm{III}}$ species indicates that the $\mathrm{ET}$ to $\mathrm{Fe}^{\mathrm{III}}$ resting state is very facile at these potentials as may be expected due to direct attachment of the Hemin-yne to the electrode. The significant intensity of ferryl species $\left(v_{2}\right.$ at $1,591 \mathrm{~cm}^{-1}$ and $v_{3}$ at $1,508 \mathrm{~cm}^{-1}$ ) entails the $\mathrm{O}-\mathrm{O}$ bond cleavage leading to its formation to be faster than its decay via reduction under steady state. Thus the reduction of the resting $\mathrm{Fe}^{\mathrm{III}}$ state, $\mathrm{O}_{2}$ binding to $\mathrm{Fe} \mathrm{II}^{\mathrm{II}}$ are facile in $\mathrm{G} 65 \mathrm{YCu}_{\mathrm{B}} \mathrm{Mb}$ under the reaction conditions. The low spin ferric species accumulated during steady state ORR could be a dioxygen adduct or peroxide adduct similar to those observed in native $\mathrm{CcO}$ and its model systems ${ }^{46-51}$. The low frequency region shows ${ }^{18} \mathrm{O}_{2}$-sensitive bands suggestive of the formation of a low spin ferric peroxide and $\mathrm{Fe}(\mathrm{IV})=\mathrm{O}$ (Supplementary Fig. 10).

If one were to conceive of a Gedanken steady state turnover experiment with $\mathrm{CcO}$ where the electron transfer to the active site is very fast (that is, in the hypothetical situation where ET from Cyt $c$ to $\mathrm{CcO}$ is not the rds) as the ET from the electrode to the active site is very fast due to direct attachment of the later to the former, the species that would accumulate during turnover, based on the Babkock-Wikström mechanism (Fig. 6, the parameters of native $\mathrm{CcO}$ are indicated in purple and $\mathrm{G} 65 \mathrm{YCu}_{\mathrm{B}} \mathrm{Mb}$ are 

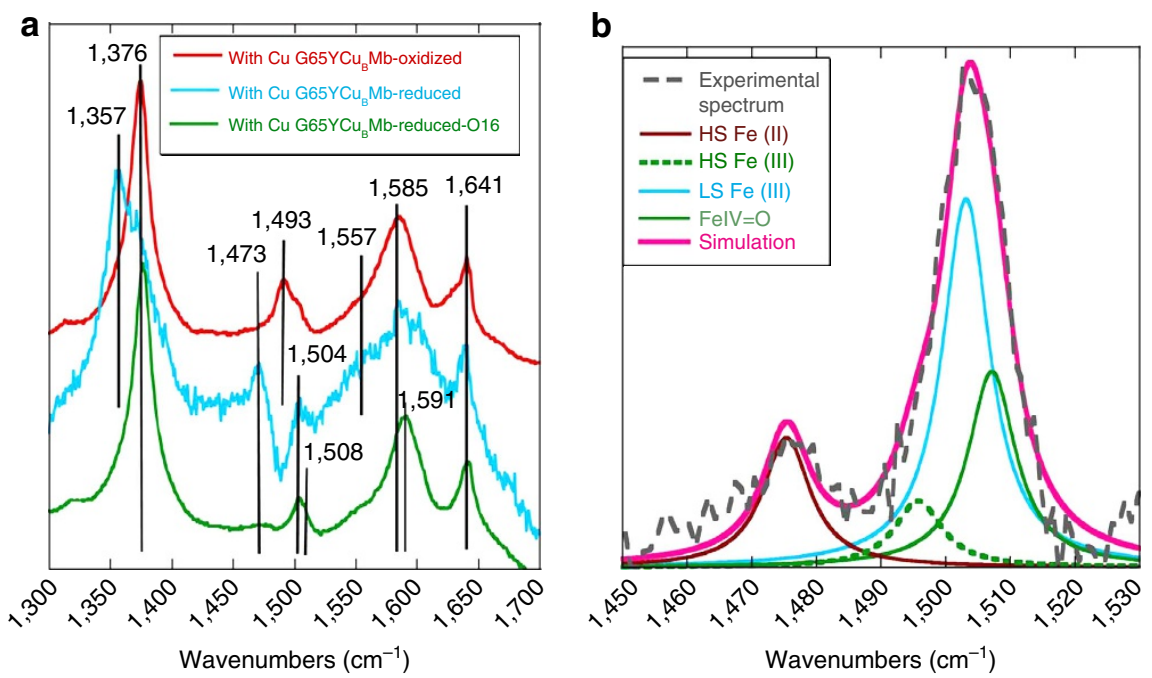

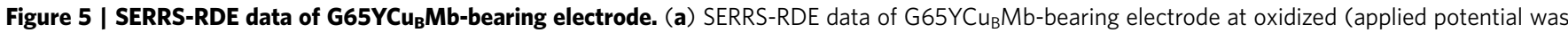
$0 \mathrm{~V}$ with respect to $\mathrm{Ag} / \mathrm{AgCl}$ reference electrode), reduced (applied potential was $-0.4 \mathrm{~V}$ with respect to $\mathrm{Ag} / \mathrm{AgCl}$ reference electrode) state and in the presence of $\mathrm{O}_{2}$ (O16) saturated $100 \mathrm{mM} \mathrm{pH} 7$ phosphate buffer and (b) Components of the rR spectrum determined by simulating the spectra of $\mathrm{G}_{65} \mathrm{YCu}_{\mathrm{B}} \mathrm{Mb}$-bearing electrode in the presence of $\mathrm{O}_{2}(\mathrm{O} 16)$ saturated $100 \mathrm{mM} \mathrm{pH} 7$ phosphate buffer indicated in green in a.

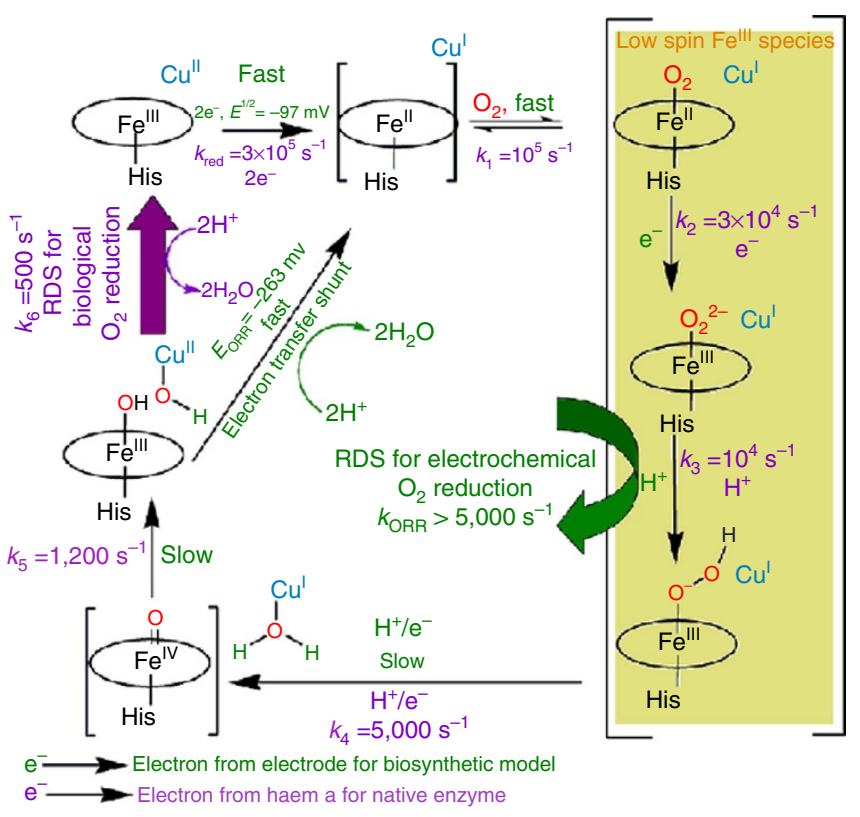

Figure 6 | Mechanisms. Comparison between the mechanism of native $\mathrm{CcO}$ (ref. 46) in solution and the biosynthetic $\mathrm{G} 65 \mathrm{YCu} \mathrm{u}_{\mathrm{B}} \mathrm{Mb}$ model on electrode.

indicated in green ${ }^{52}$ and the arrows in black indicate general route for $\mathrm{O}_{2}$ reduction by $\mathrm{CcO}$ followed in both the native system, as well as in the $\mathrm{G}_{6} 5 \mathrm{YCu}_{\mathrm{B}} \mathrm{Mb}$-immobilized electrode) are the $\mathrm{Fe}^{\mathrm{II}}, \mathrm{Fe}^{\mathrm{II}}-\mathrm{O}_{2}, \quad \mathrm{Fe}^{\mathrm{III}}-\mathrm{O}_{2}^{2-}, \mathrm{Fe}^{\mathrm{III}}-\mathrm{OOH}, \quad \mathrm{Fe}^{\mathrm{IV}}=\mathrm{O}$ and $\mathrm{Fe}^{\mathrm{III}}-\mathrm{OH}$ species as the rates of formation of these species are greater than their rates of decay ${ }^{53,54}$. Out of these, the $\mathrm{Fe}^{\mathrm{II}}-\mathrm{O}_{2}, \mathrm{Fe}^{\mathrm{III}_{-}} \mathrm{O}_{2}^{2-}$ and $\mathrm{Fe}^{\mathrm{III}}-\mathrm{OOH}$ species will have Raman signatures of low spin haem (Fig. 6), $\mathrm{Fe}^{\mathrm{II}}$-OH will have rR signature of high spin haem and the $\mathrm{Fe}^{\mathrm{IV}}=\mathrm{O}$ will have signatures unique to haem ferryl species ${ }^{46,54,55}$. The SERRS-RDE data show the presence of species having signatures of low spin $\mathrm{Fe}^{\mathrm{III}}$ and $\mathrm{Fe}^{\mathrm{IV}}=\mathrm{O}$. While the later can originate from only a single species, the former can indicate the presence of any of the three species or a combination of them. The lack of significant high spin signal indicates that the biosynthetic model circumvents accumulation of $\mathrm{Fe}^{\mathrm{III}}-\mathrm{OH}$ and resting Fe ${ }^{\mathrm{III}}$ species in the steady state by facile ET. The overall rate-limiting step of native $\mathrm{CcO}$ in solution is the dissociation of hydroxide of the $\mathrm{Fe}^{\mathrm{III}}-\mathrm{OH}$ end product of $\mathrm{O}_{2}$ reduction from haem to generate the active ferric resting form and has a first order rate constant of $500 \mathrm{~s}^{-1}$ (refs 46,54-56). This dissociation is required during turnover as the potential of this hydroxidebound form is likely to be more negative that the five-coordinate resting oxidized site (which will be regenerated after hydroxide dissociation) and will not be reduced by haem a. While the $E^{1 / 2}$ of a haem $\mathrm{a}_{3} \mathrm{Fe}^{\mathrm{III}}$-OH species cannot be determined with confidence due to strong interaction potential and co-operativity between the haem a and haem $a_{3}$ sites, the potential of formate and azidebound high spin haem $a_{3}$ site (analogous to hydroxide) is $\sim 130$ to $200 \mathrm{mV}$ more negative than the resting ferric site ${ }^{57,58}$. The potential determining step of ORR (defined as the electron transfer (ET) step in catalysis having lowest potential) by the $\mathrm{G} 65 \mathrm{YCu}_{\mathrm{B}} \mathrm{Mb}$ is $166 \mathrm{mV}$ more negative than the $E^{1 / 2}$ for the resting high spin ferric state and is likely to be the reduction of the $\mathrm{Fe}^{\mathrm{III}}$-OH species. Thus the bioelectrode can circumvent the kinetic barrier associated with the dissociation of the hydroxide by directly reducing it to ferrous at $166 \mathrm{mV}$ lower potential. This direct electron transfer to the ferric hydroxide species, which is an intermediate in the catalytic cycle of $\mathrm{CcO}$, circumventing a slow step in catalysis, is an electron transfer shunt analogous to peroxide shunt in cytochrome $\mathrm{P} 450$, which overcomes the ratedetermining $\mathrm{O}_{2}$ activation step of the native enzyme ${ }^{59}$. In the mass transfer controlled region of the catalytic current, all ET steps are facile and steps like $\mathrm{O}_{2}$ binding, protonation and $\mathrm{O}-\mathrm{O}$ bond cleavage can be rds at these potential. The lack of $\mathrm{HS} \mathrm{Fe}^{\mathrm{II}}$ accumulation in the SERRS-RDE indicates that $\mathrm{O}_{2}$ binding to $\mathrm{Fe}^{\mathrm{II}}$ is very fast and not the rds. The $\mathrm{O}-\mathrm{O}$ bond cleavage in the Babkock-Wikström mechanism involves ET to the active site and not the rds as well. Thus rds of ORR by these biosynthetic models is likely to be the protonation of the $\mathrm{Fe}^{\mathrm{III}}-\mathrm{O}_{2}^{-}$species with a first order rate of $5,000 \mathrm{~s}^{-1}$ (Fig. 6).

In an air-saturated buffer $\left(0.26 \mathrm{mM} \mathrm{O}_{2}\right)$, the pseudo first order rate constant of ORR by $\mathrm{G} 65 \mathrm{YCu}_{\mathrm{B}} \mathrm{Mb}$ is determined to be $\sim 5-6 \times 10^{3} \mathrm{~s}^{-1}\left(k_{\mathrm{ORR}}\left[\mathrm{O}_{2}\right]\right)$.The highest second order $\mathrm{O}_{2}$ reduction rate reported for any synthetic mimic of $\mathrm{CcO}$ is $1.2 \times$ $10^{5} \mathrm{M}^{-1} \mathrm{~s}^{-1}$; that too on a multilayer having 1,000 times more catalyst than the $\mathrm{G}_{65} \mathrm{YCu}_{\mathrm{B}} \mathrm{Mb}$ electrodes ${ }^{60}$. The second order rate 
constant of $\mathrm{G} 65 \mathrm{YCu}_{\mathrm{B}} \mathrm{Mb}$ is $10^{7} \mathrm{M}^{-1} \mathrm{~s}^{-1}$ which is, thus, 2 orders of magnitude higher than best synthetic haem/Cu-based $\mathrm{O}_{2}$ reduction electrocatalyst. Thus the selectivity and kinetic rate of the $\mathrm{G} 65 \mathrm{YCu}_{\mathrm{B}} \mathrm{Mb}$-bearing electrode surpasses those reported for smaller synthetic analogues and illustrates the advantages of using a biochemical scaffold over a synthetic scaffold. Although the pseudo first order rate constant of the $\mathrm{G} 65 \mathrm{YCu}_{\mathrm{B}} \mathrm{Mb}$ is 10 times faster than the rate of native $\mathrm{CcO}$ in solution, such a comparison is vulnerable to differences in reaction conditions (for example, $\mathrm{G} 65 \mathrm{YCu}_{\mathrm{B}} \mathrm{Mb}$ is water soluble but $\mathrm{CcO}$ exists in membranes). Alternatively, erstwhile efforts resulting in electrodes bearing native $\mathrm{CcO}$ in a manner similar to these bio-electrodes show extremely sluggish $\mathrm{O}_{2}$ reduction ${ }^{60-62}$. This is due to improper alignment of this membrane-bound protein on the electrode, which precludes efficient electron transfer to the active site ${ }^{63-65}$. However, the direct attachment of haem to the electrode utilizing its solvent-exposed propionate groups (that is, a short circuit) enables fast electron transfer to the active site $e^{29}$. This is further supported by the fact that when ethynylferrocene $(\mathrm{Fc})$ is attached to the same surface $\sim 25 \mathrm{mV}$ peak separation is observed even at $5 \mathrm{~V} \mathrm{~s}^{-1}$ (Supplementary Fig. 11) ${ }^{38}$, suggesting that the ET is indeed fast. As a result when a $\mathrm{CcO}$-functionalized SAM-covered $\mathrm{Au}$ electrode produces $<1 \mu \mathrm{A}$ electrochemical $\mathrm{O}_{2}$ reduction current at $-300 \mathrm{mV}$, this bio-electrode produce $\sim 100 \mu \mathrm{A}$ current at similar potentials ${ }^{66}$.

Finally, the $\mathrm{G} 65 \mathrm{YCu}_{\mathrm{B}} \mathrm{Mb}$ mutant has residues in the distal pocket that can help both electron and proton transfer during $\mathrm{O}_{2}$ reduction ( $\mathrm{Y} 65$ in $\mathrm{G} 65 \mathrm{YCu}_{\mathrm{B}} \mathrm{Mb}$ ). In $\mathrm{CcO}$, the involvement of Tyr 244 residues in proton/electron transfer during $\mathrm{O}_{2}$ reduction is now widely accepted ${ }^{67,68}$. Previous biochemical and structural studies on these mutants had indeed indicated the close proximity of this residue to the distal site , $^{79,30}$. An analogous biochemical model without the $\mathrm{Y} 65$ residue, $\mathrm{Cu}_{\mathrm{B}} \mathrm{Mb}$, is not as stable as the $\mathrm{G} 65 \mathrm{YCu}_{\mathrm{B}} \mathrm{Mb}$ as the former degrades rapidly during the $\mathrm{RDE}$ experiments (Supplementary Fig. 12). In summary, a electron transfer shunt which circumvents the rate-determining dissociation of a ferric hydroxide species by directly reducing it at slightly negative potential, fast $\mathrm{O}_{2}$ binding, fast electron transfer to the active site and the presence of a protective $\mathrm{Y} 65$ residue in a biochemical model of $\mathrm{CcO}$ results in $\mathrm{O}_{2}$ reduction activity 100 times faster than the best synthetic models, order of magnitude faster than $\mathrm{CcO}$ immobilized on electrode and follows a mechanism comparable to that of native $\mathrm{CcO}$ in solution.

\footnotetext{
Methods

Materials. 1-Azidoundecane-11-thiol and Hemin-yne were synthesized following the reported procedure ${ }^{29,69}$. 6-Mercaptohexanoic acid was purchased from Sigma Aldrich. Di-sodium hydrogenphosphate dihydrate $\left(\mathrm{Na}_{2} \mathrm{HPO}_{4} \cdot 2 \mathrm{H}_{2} \mathrm{O}\right)$ was purchased from Merck. 2, 6-lutidine was purchased from Avra Synthesis Pvt. Ltd. These chemicals were used without further purification. Au wafers were purchased from Platypus Technologies $(1,000 \AA$ of $\mathrm{Au}$ on $50 \AA$ of $\mathrm{Ti}$ adhesion layer on top of a Si(III) surface). Transparent Au wafers (100 $\AA$ of $A u$ on $10 \AA$ of Ti) were purchased from Phasis, Switzerland. Au and Ag discs for the RRDE and SERRS experiments, respectively, were purchased from Pine Instruments, USA. $\mathrm{The} \mathrm{Mb}$ mutants were prepared as reported in the literature ${ }^{7,30}$. Analysis of the components of the rR spectrum was done by using Lorenztian line shape of peak fit software.

Instrumentation. All electrochemical experiments were performed using a $\mathrm{CH}$ Instruments (model CHI710D Electrochemical Analyzer). Bipotentiostat, reference electrode and Teflon plate material evaluating cell (ALS, Japan; http://www.als-japan.com/1398.html) were purchased from CH Instruments. The RRDE set-up from Pine Research Instrumentation (E6 series ChangeDisk tips with AFE6M rotor) was used to obtain the RRDE data. The mutant Mb-functionalized or SAM-covered Au surface (disc of $0.1 \mathrm{~cm}^{2}$ area for RDE, RRDE and wafer of $0.45 \mathrm{~cm}^{2}$ area for $\mathrm{CV}$ ) was always used as the working electrode. The XPS data were collected in a Omicron (model: 1712-62-11) spectrometer using a high-resolution
} monochromatic $\mathrm{Al}-\mathrm{K} \alpha$ source at $1,486.7 \mathrm{eV}$ under $15 \mathrm{kV}$ voltage and $10 \mathrm{~mA}$ current maintaining a base pressure of $5 \times 10^{-10} \mathrm{mbar}$. The binding energies were calibrated to the $\mathrm{Ag} 3 \mathrm{~d}_{5 / 2}$ peak at $368.2 \mathrm{eV}$. The resonance Raman experiments were done in the $\mathrm{Kr}^{+}$Laser (Sabre Innova, Model-SBRC-DBW-K) purchased from Coherent, and the data were collected using the Spectrograph (ModelTrivista 555) from Princeton Instruments.

Formation of mixed SAM and covalent attachment of Hemin-yne to it. Mixed self-assembled monolayer of 1-azidoundecan-11-thiol and 6-mercaptohexanoic acid was formed on immersing the properly cleaned Au wafers or disks into the deposition solution containing 1-azidoundecan-11-thiol and 6-mercaptohexanoic acid in $10 \mathrm{ml}$ of ethanol in a desired ratio (typically 1:49). The total thiol concentration of these deposition solutions were always maintained at $1 \mathrm{mM}$. On this SAM Hemin-yne was covalently attached using 'Click' reaction ${ }^{29}$.

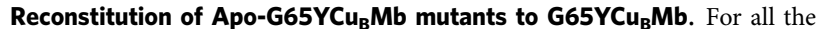
experiments on heterogeneous SAM surfaces, the Hemin-yne modified $-\mathrm{COOH}$ SAM surfaces were incubated with a $20 \mu \mathrm{M}$ apoprotein (Apo-G65YCu $\mathrm{Cu}_{\mathrm{B}} \mathrm{Mb}$ ) solution for $2 \mathrm{~h}$. The supernatant solution was drained and the surface was cleaned with water. The presence of $\mathrm{Cu}^{2+}$ in the non-haem-binding site is confirmed by electron paramagnetic resonance (EPR) spectroscopy (Supplementary Fig. 13). The immobilization of the mutant is further confirmed by the absorption spectra and SERRS of the surface fabricated with those mutants (Supplementary Fig. 14, Supplementary Fig. 15).

Cyclic voltammetry. The CV was performed using Au wafers sandwiched between two Teflon blocks of the Plate material evaluating cell. All electrochemical experiments were done in $\mathrm{pH} 7$ phosphate buffer containing potassium hexafluorophosphate. Anaerobic cyclic voltammetric experiments were done by using degassed buffer (three cycles of freeze-pump-thaw). $\mathrm{Ag} / \mathrm{AgCl}$ reference electrode and Pt counter electrode were used throughout all the electrochemical experiments except the case of anaerobic experiments where only Ag wire was used as the reference electrode.

The peak areas were estimated by integrating the anodic/cathodic peak of the anaerobic CV of the mutant Mb-functionalized SAM-covered Au surface, using the data acquisition software itself. A line collinear with the background is used to subtract the background. The estimated area has been further confirmed by subtracting the background current of a SAM-functionalized electrode (Supplementary Fig. 11) bearing ferrocene. Both these approaches provide the same estimate.

To ensure that the SAM surface is stable during the electrocatalytic investigations, disc bearing just the SAM was subjected to several rotations (200-1,000 r.p.m.) and its capacitive current was found not to change, indicating that the SAM is retained on the electrode during these dynamic electrochemistry experiments (Supplementary Fig. 16). SAM can also be damaged when the protein atop the SAM degrades during ORR due to the reactive oxygen species produced When an unstable electrocatalyst (Hemin-yne) decayed there was a steady loss of ORR current, indicating degradation of the active site but the capacitive currents of the SAM were unaltered (Supplementary Fig. 17).

SERRS and SERRS-RDE. The excitation wavelength used in the Resonance Raman experiments was $406.7 \mathrm{~nm}$ and the power applied to the sample was $10-15 \mathrm{~mW}$. The spectrograph was calibrated against naphthalene. The Ag surfaces were roughened before SERRS experiments following literature protocols ${ }^{70}$. The SERRS RDE set-up is described in ref. 42 . The data for the oxidized state was obtained by holding the potential of the disc at $0 \mathrm{mV}$ versus NHE, and the data during steady state ORR was obtained by holding the disc at $-400 \mathrm{mV}$ versus NHE and the disc was rotated at 300 r.p.m. Normally data were acquired over a period of $300 \mathrm{~s}$.

\section{References}

1. Collman, J. P. et al. A cytochrome c oxidase model catalyzes oxygen to water reduction under rate-limiting electron flux. Science 315, 1565-1568 (2007).

2. Mirica, L. M. et al. Tyrosinase reactivity in a model complex: an alternative hydroxylation mechanism. Science 308, 1890-1892 (2005).

3. Wang, Y., DuBois, J. L., Hedman, B., Hodgson, K. O. \& Stack, T. D. Catalytic galactose oxidase models: biomimetic $\mathrm{Cu}(\mathrm{II})$-phenoxyl-radical reactivity. Science 279, 537-540 (1998).

4. Beinert, H., Holm, R. H. \& MÃ $\frac{1}{4}$ nck, E. Iron-sulfur clusters: nature's modular, multipurpose structures. Science 277, 653-659 (1997).

5. Cole, A. P., Root, D. E., Mukherjee, P., Solomon, E. I. \& Stack, T. D. P. A trinuclear intermediate in the copper-mediated reduction of $\mathrm{O} 2$ : four electrons from three coppers. Science (Washington, D. C.) 273, 1848-1850 (1996).

6. Robertson, D. E. et al. Design and synthesis of multi-heme proteins. Nature (London) 368, 425-432 (1994).

7. Yeung, N. et al. Rational design of a structural and functional nitric oxide reductase. Nature 462, 1079-1082 (2009).

8. Tard, C. et al. Synthesis of the H-cluster framework of iron-only hydrogenase. Nature 433, 610-613 (2005). 
9. Aboelella, N. W. et al. Effects of thioether substituents on the $\mathrm{O}_{2}$ reactivity of $\beta$ diketiminate- $\mathrm{Cu}(\mathrm{I})$ complexes: probing the role of the methionine ligand in copper monooxygenases. J. Am. Chem. Soc. 128, 3445-3458 (2006).

10. Shin, H., Lee, D.-H., Kang, C. \& Karlin, K. D. Electrocatalytic four-electron reductions of $\mathrm{O}_{2}$ to $\mathrm{H}_{2} \mathrm{O}$ with cytochrome c oxidase model compounds. Electrochim. Acta 48, 4077-4082 (2003).

11. Kim, E. et al. Superoxo, $\mu$-peroxo, and $\mu$-oxo complexes from heme/ $\mathrm{O}_{2}$ and heme- $\mathrm{Cu} / \mathrm{O}_{2}$ reactivity: Copper ligand influences in cytochrome $\mathrm{c}$ oxidase models. Proc. Natl Acad. Sci. USA 100, 3623-3628 (2003).

12. Tolman, W. B. \& Que, J. L. Sterically hindered benzoates: a synthetic strategy for modeling dioxygen activation at diiron active sites in proteins. J. Chem. Soc. Dalton Trans. 31, 653-660 (2002).

13. Osyczka, A., Moser, C. C., Daldal, F. \& Dutton, P. L. Reversible redox energy coupling in electron transfer chains. Nature 427, 607-612 (2004).

14. Koder, R. L. et al. Design and engineering of an $\mathrm{O} 2$ transport protein. Nature 458, 305-309 (2009).

15. Page, C. C., Moser, C. C., Chen, X. \& Dutton, P. L. Natural engineering principles of electron tunneling in biological oxidation-reduction. Nature 402, 47-52 (1999).

16. Tani, F., Matsu-ura, M., Nakayama, S. \& Naruta, Y. Synthetic models for the active site of cytochrome P450. Coord. Chem. Rev. 226, 219-226 (2002).

17. Dey, A. et al. Solvent tuning of electrochemical potentials in the active sites of HiPIP versus ferredoxin. Science 318, 1464-1468 (2007).

18. Astrow, M. L., Peacock, A. F. A., Stuckey, J. A. \& Pecoraro, V. L. Hydrolytic catalysis and structural stabilization in a designed metalloprotein. Nat. Chem. 4, 118-123 (2012).

19. Lin, Y.-W. et al. Roles of glutamates and metal ions in a rationally designed nitric oxide reductase based on myoglobin. Proc. Natl Acad. Sci. USA. 107, 8581-8586 (2010).

20. Esselborn, J. et al. Spontaneous activation of [FeFe]-hydrogenases by an inorganic [2Fe] active site mimic. Nat. Chem. Biol. 9, 607-609 (2013).

21. Fontecave, M. \& Artero, V. Bioinspired catalysis at the crossroads between biology and chemistry: A remarkable example of an electrocatalytic material mimicking hydrogenases. C. R. Chim. 14, 362-371 (2011).

22. Lu, Y. \& Valentine, J. S. Engineering metal-binding sites in proteins. Curr. Opin. Struct. Biol. 7, 495-500 (1997).

23. Cracknell, J. A. \& Blanford, C. F. Developing the mechanism of dioxygen reduction catalyzed by multicopper oxidases using protein film electrochemistry. Chem. Sci. 3, 1567-1581 (2012).

24. dos Santos, L., Climent, V., Blanford, C. F. \& Armstrong, F. A. Mechanistic studies of the 'blue' $\mathrm{Cu}$ enzyme, bilirubin oxidase, as a highly efficient electrocatalyst for the oxygen reduction reaction. Phys. Chem. Chem. Phys. 12, 13962-13974 (2010).

25. Sigman, J. A., Kim, H. K., Zhao, X., Carey, J. R. \& Lu, Y. The role of copper and protons in heme-copper oxidases: kinetic study of an engineered heme-copper center in myoglobin. Proc. Natl Acad. Sci. USA. 100, 3629-3634 (2003).

26. Bhagi-Damodaran, A., Petrik, I. D., Marshall, N. M., Robinson, H. \& Lu, Y. Systematic tuning of heme redox potentials and its effects on $\mathrm{O} 2$ reduction rates in a designed oxidase in myoglobin. J. Am. Chem. Soc. 136, 11882-11885 (2014).

27. Blanford, C. F., Foster, C. E., Heath, R. S. \& Armstrong, F. A. Efficient electrocatalytic oxygen reduction by the 'blue' copper oxidase, laccase, directly attached to chemically modified carbons. Faraday Discuss. 140, 319-335 (2009).

28. Blanford, C. F., Heath, R. S. \& Armstrong, F. A. A stable electrode for highpotential, electrocatalytic $\mathrm{O}_{2}$ reduction based on rational attachment of a blue copper oxidase to a graphite surface. Chem. Commun. 43, 1710-1712 (2007).

29. Mukherjee, S., Sengupta, K., Das, M. R., Jana, S. S. \& Dey, A. Site-specific covalent attachment of heme proteins on self-assembled monolayers. J. Biol. Inorg. Chem. 17, 1009-1023 (2012).

30. Sigman, J. A., Kwok, B. C. \& Lu, Y. From myoglobin to heme-copper oxidase: design and engineering of a $\mathrm{CuB}$ center into sperm whale myoglobin. J. Am. Chem. Soc. 122, 8192-8196 (2000).

31. Miner, K. D. et al. A designed functional metalloenzyme that reduces $\mathrm{O} 2$ to $\mathrm{H} 2 \mathrm{O}$ with over one thousand turnovers. Angew. Chem. Int. Ed. 51, 5589-5592 (2012).

32. Hu, S., Smith, K. M. \& Spiro, T. G. Assignment of protoheme resonance Raman spectrum by heme labeling in myoglobin. J. Am. Chem. Soc. 118, 12638-12646 (1996).

33. Bandyopadhyay, S., Mukherjee, S. \& Dey, A. Modular synthesis, spectroscopic characterization and in situ functionalization using "click" chemistry of azide terminated amide containing self-assembled monolayers. RSC Adv. 3, 17174-17187 (2013)

34. Guo, L.-H., McLendon, G., Razafitrimo, H. \& Gao, Y. Photo-active and electroactive protein films prepared by reconstitution with metalloporphyrins selfassembled on gold. J. Mater. Chem. 6, 369-374 (1996).

35. Ghodselahi, T., Vesaghi, M. A., Shafiekhani, A., Baghizadeh, A. \& Lameii, M. XPS study of the Cu@Cu2O core-shell nanoparticles. Appl. Surf. Sci. 255, 2730-2734 (2008).
36. Schmitt, S. K., Murphy, W. L. \& Gopalan, P. Crosslinked PEG mats for peptide immobilization and stem cell adhesion. J. Mater. Chem. B 1, 1349-1360 (2013).

37. Boulatov, R., Collman, J. P., Shiryaeva, I. M. \& Sunderland, C. J. Functional analogues of the dioxygen reduction site in cytochrome oxidase: mechanistic aspects and possible effects of $\mathrm{Cu}_{\mathrm{B}}$. J. Am. Chem. Soc. 124, 11923-11935 (2002).

38. Mukherjee, S., Bandyopadhyay, S. \& Dey, A. Tuning the apparent formal potential of covalently attached ferrocene using SAM bearing ionizable $\mathrm{COOH}$ groups. Electrochim. Acta 108, 624-633 (2013).

39. Bard, A. J. \& Faulkner, L. R. Electrochemical Methods: Fundamentals and Applications 2nd edn (Wiley, 1980).

40. McCrory, C. C. L. et al. Electrocatalytic O2 reduction by covalently immobilized mononuclear copper(I) complexes: evidence for a binuclear Cu2O2 intermediate. J. Am. Chem. Soc. 133, 3696-3699 (2011).

41. Shi, C. \& Anson, F. C. Potential-dependence of the reduction of dioxygen as catalysed by tetraruthenated cobalt tetrapyridylporphyrin. Electrochim. Acta 39, 1613-1619 (1994).

42. Sengupta, K., Chatterjee, S., Samanta, S. \& Dey, A. Direct observation of intermediates formed during steady-state electrocatalytic $\mathrm{O}_{2}$ reduction by iron porphyrins. Proc. Natl Acad. Sci. USA 110, 8431-8436 (2013).

43. Oertling, W. A., Kean, R. T., Wever, R. \& Babcock, G. T. Factors affecting the iron-oxygen vibrations of ferrous oxy and ferryl oxo heme proteins and model compounds. Inorg. Chem. 29, 2633-2645 (1990).

44. Sono, M., Smith, P. D., McCray, J. A. \& Asakura, T. Kinetic and equilibrium studies of the reactions of heme-substituted horse heart myoglobins with oxygen and carbon monoxide. J. Biol. Chem. 251, 1418-1426 (1976).

45. Nagao, S. et al. Structural and oxygen binding properties of dimeric horse myoglobin. Dalton Trans. 41, 11378-11385 (2012).

46. Ferguson-Miller, S. \& Babcock, G. T. Heme/copper terminal oxidases. Chem. Rev. 96, 2889-2908 (1996).

47. Iwata, S., Ostermeier, C., Ludwig, B. \& Michel, H. Structure at 2.8 A resolution of cytochrome c oxidase from Paracoccus denitrificans. Nature 376, 660-669 (1995).

48. Collman, J. P. \& Decreau, R. A. Functional biomimetic models for the active site in the respiratory enzyme cytochrome c oxidase. Chem. Commun. 44, 5065-5076 (2008).

49. Garcia-Bosch, I. et al. A "naked" $\mathrm{Fe}^{\mathrm{III}}-\left(\mathrm{O}_{2}^{2-}\right)-\mathrm{Cu}^{\mathrm{II}}$ species allows for structural and spectroscopic tuning of low-spin heme-peroxo-Cu complexes. J. Am. Chem. Soc. 137, 1032-1035 (2015).

50. Kim, E., Chufan, E. E., Kamaraj, K. \& Karlin, K. D. Synthetic models for hemecopper oxidases. Chem. Rev. 104, 1077-1134 (2004).

51. Kim, E. et al. Dioxygen reactivity of copper and heme-copper complexes possessing an imidazole-phenol cross-link. Inorg. Chem. 44, 1238-1247 (2005).

52. Babcock, G. T. \& Wikstrom, M. Oxygen activation and the conservation of energy in cell respiration. Nature 356, 301-309 (1992).

53. Varotsis, C., Zhang, Y., Appelman, E. H. \& Babcock, G. T. Resolution of the reaction sequence during the reduction of oxygen by cytochrome oxidase. Proc Natl Acad. Sci. USA 90, 237-241 (1993).

54. Han, S., Takahashi, S. \& Rousseau, D. L. Time dependence of the catalytic intermediates in cytochrome c oxidase. J. Biol. Chem. 275, 1910-1919 (2000).

55. Han, S., Ching, Y.-C. \& Rousseau, D. L. Ferryl and hydroxy intermediates in the reaction of oxygen with reduced cytochrome c oxidase. Nature 348, 89-90 (1990).

56. Rousseau, D. L. Bioenergetics: two phases of proton translocation. Nature 400, 412-413 (1999).

57. Kojima, N. \& Palmer, G. Further characterization of the potentiometric behavior of cytochrome oxidase. Cytochrome a stays low spin during oxidation and reduction. J. Biol. Chem. 258, 14908-14913 (1983).

58. Namslauer, A., Branden, M. \& Brzezinski, P. The rate of internal heme-heme electron transfer in cytochrome c oxidase. Biochemistry 41, 10369-10374 (2002)

59. Denisov, I. G., Makris, T. M., Sligar, S. G. \& Schlichting, I. Structure and chemistry of cytochrome P450. Chem. Rev. 105, 2253-2278 (2005).

60. Boulatov, R., Collman, J. P., Shiryaeva, I. M. \& Sunderland, C. J. Functional analogues of the dioxygen reduction site in cytochrome oxidase:mechanistic aspects and possible effects of CuB. J. Am. Chem. Soc. 124, 11923-11935 (2002).

61. Friedrich, M. G. et al. In situ monitoring of the catalytic activity of cytochrome c oxidase in a biomimetic architecture. Biophys. J. 95, 1500-1510 (2008).

62. Haas, A. S. et al. Cytochrome $\mathrm{c}$ and cytochrome $\mathrm{c}$ oxidase: monolayer assemblies and catalysis. J. Phys. Chem. B 105, 11351-11362 (2001).

63. Burgess, J. D., Rhoten, M. C. \& Hawkridge, F. M. Cytochrome c oxidase immobilized in stable supported lipid bilayer membranes. Langmuir 14, 2467-2475 (1998).

64. Naumann, R. et al. The peptide-tethered lipid membrane as a biomimetic system to incorporate cytochrome c oxidase in a functionally active form. Biosens. Bioelectron. 14, 651-662 (1999).

65. Burgess, J. D., Jones, V. W., Porter, M. D., Rhoten, M. C. \& Hawkridge, F. M. Scanning force microscopy images of cytochrome c oxidase immobilized in an electrode-supported lipid bilayer membrane. Langmuir 14, 6628-6631 (1998). 
66. Su, L., Kelly, J. \& Hawkridge, F. M. Electroreduction of $\mathrm{O}_{2}$ on cytochrome c oxidase modified electrode for biofuel cell. ECS Trans. 2, 1-6 (2007).

67. Yoshikawa, S., Muramoto, K. \& Shinzawa-Itoh, K. Proton-pumping mechanism of cytochrome c oxidase. Annu. Rev. Biophys. 40, 205-223 (2011).

68. Morgan, J. E., Verkhovsky, M. I., Palmer, G. \& Wikström, M. Role of the PR intermediate in the reaction of cytochrome c oxidase with $\mathrm{O} 2$. Biochemistry 40, 6882-6892 (2001)

69. Collman, J. P., Devaraj, N. K., Eberspacher, T. P. A. \& Chidsey, C. E. D. Mixed azide-terminated monolayers: a platform for modifying electrode surfaces. Langmuir 22, 2457-2464 (2006).

70. Arūnas Bulovas, Z. T. et al. Double-layered Ag/Au electrode for SERS spectroscopy: preparation and application for adsorption studies of chromophoric compounds. Chemija 18, 9-15 (2007).

\section{Acknowledgements}

This research is sponsored by Department of Science and Technology, India and US National Institute of Health (GM062211).

\section{Author contributions}

S.M. acquired all the data, analysed the data and wrote the paper. A.M. and A.B. purified and provided the mutant proteins and helped write the paper. M.M. helped S.M. in

acquiring some data. Y.L. provided the proteins, helped write the paper and developed the science. A.D. conceived the study, analysed the data, developed the science and wrote the paper

\section{Additional information}

Supplementary Information accompanies this paper at http://www.nature.com/ naturecommunications

Competing financial interests: The authors declare no competing financial interests.

Reprints and permission information is available online at http://npg.nature.com/ reprintsandpermissions/

How to cite this article: Mukherjee, S. et al. A biosynthetic model of cytochrome $c$ oxidase as an electrocatalyst for oxygen reduction. Nat. Commun. 6:8467 doi: $10.1038 /$ ncomms 9467 (2015)

\section{(c) (1)}

This work is licensed under a Creative Commons Attribution 4.0 International License. The images or other third party material in this article are included in the article's Creative Commons license, unless indicated otherwise in the credit line; if the material is not included under the Creative Commons license, users will need to obtain permission from the license holder to reproduce the material. To view a copy of this license, visit http://creativecommons.org/licenses/by/4.0/ 